\title{
The hereditary angioedema burden of illness study in Europe (HAE-BOIS-Europe): background and methodology
}

\author{
Anette Bygum ${ }^{*}$, Emel Aygören-Pürsün ${ }^{2}$, Teresa Caballero ${ }^{3}$, Kathleen Beusterien ${ }^{4}$, Shadi Gholizadeh ${ }^{4}$, \\ Patience Musingarimi ${ }^{5}$, Suzanne Wait ${ }^{6}$ and Henrik Boysen ${ }^{7}$
}

\begin{abstract}
Background: Hereditary angioedema (HAE) is a rare but serious disease marked by swelling attacks in the extremities, face, trunk, airway, or abdominal areas that can be spontaneous or the result of trauma and other triggers. It can be life-threatening due to the risk of asphyxiation. While there have been major advancements in our understanding of the immunogenetics of HAE, there are significant gaps in the literature regarding understanding of the humanistic and economic impact of the disease, particularly in Europe. The purpose of the HAE Burden of Illness Study-Europe (HAE-BOIS-Europe), the development and methodology of which is described here, is to better understand the management and impact of HAE from the patient perspective in Europe.

Methods/Design: This is a cross-sectional study, in which current and retrospective data are collected, conducted in Denmark, Germany and Spain. The study is open to patients ages 12 and older with a diagnosis of HAE-I or HAEII. Data collection includes: (i) a survey on individuals' health care resource use, direct and indirect medical costs, impact on work and school, treatment satisfaction, and emotional functioning (via the Hospital Anxiety and Depression Scale); and (ii) one-on-one interviews to collect detailed descriptive data and patient testimonials on the impact of HAE on patients' health-related quality of life.
\end{abstract}

Discussion: The present manuscript describes the development and plans for implementing a multi-country European study with the aim of characterizing the humanistic and economic burden of HAE from the patient perspective. This study will help raise awareness of HAE as a rare but debilitating condition with wide-ranging impacts.

\section{Background}

Hereditary angioedema (HAE) is a rare but serious autosomal dominant disorder marked by swelling attacks in the extremities, face, trunk, airways, or abdominal areas that can be spontaneous or the result of trauma [1] (Figure 1). Attacks can be serious; the risk of dying from airway obstruction, if left untreated, has been estimated at $30 \%[2,3]$. Attack frequency is described in the literature as ranging from rarely to once every 3 days [4]. Untreated, patients on average experience attacks every one to two weeks [5].

The prevalence of HAE is estimated to be approximately 1 in every 50,000 persons, with no marked

\footnotetext{
* Correspondence: Anette.Bygum@ouh.regionsyddanmark.dk

'HAE Centre Denmark, Department of Dermatology and Allergy Centre,

Odense University Hospital, 5000 Odense C, Denmark

Full list of author information is available at the end of the article
}

differences among ethnic groups [6,7]. The rarity of the disease, together with the fact that $6.1-13.7 \%$ of patients may be asymptomatic or have delayed symptom onset [7-9], means that, while HAE symptoms often begin in early childhood and persist throughout patients' lives, awareness of the condition is extremely low, and diagnosis is frequently delayed. As observed in a Danish study, the mean delay to diagnosis can be as great as 16 years [7]. There is therefore an urgent need to raise awareness of the disease and its appropriate diagnosis and treatment among clinicians and families who have a hereditary predisposition to the condition.

Improvements in our understanding of the disease process have led to the recent availability of an increased range of treatment options for HAE. Disease management takes the form of treatment of acute attacks, shortterm prophylactic treatment for the prevention of attacks

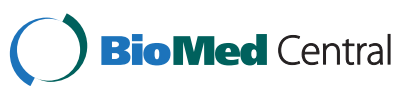



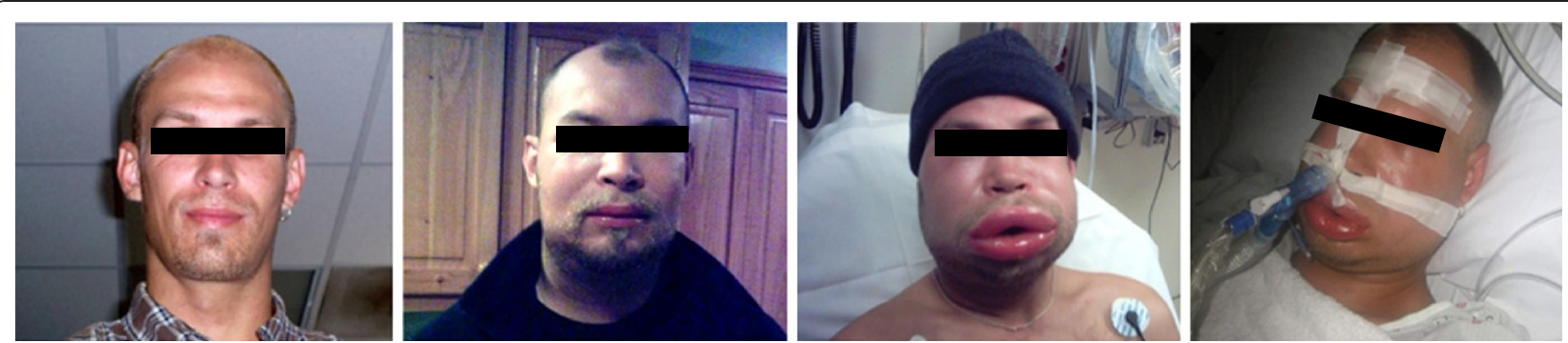

Figure 1 HAE patient experiencing HAE attacks.

(for example, before a surgical procedure), and long-term prophylactic treatment (prevention) to minimize the frequency and severity of ongoing attacks $[5,10,11]$. Treatments currently approved in Europe for acute attacks include plasma derived (pd) C1-inhibitor [human] concentrate (Berinert, Cetor), pd nano-filtered C1-inhibitor [human] (Cinryze), recombinant C1-inhibitor (Ruconest/ Rhucin), and use of a bradykinin B2 receptor antagonist (Firazyr). Long-term prophylaxis (prevention) options have traditionally involved androgens (such as danazol or stanozolol), although their approval status for HAE varies among European countries. Cinryze is the only agent to have received European approval for both the treatment and pre-procedure prevention of angioedema attacks in adults and adolescents with HAE, as well as for the routine prevention of angioedema attacks in adults and adolescents.

The mechanisms underlying what prompts HAE attacks to start and resolve are relatively unknown. Moreover, the severity of symptoms is highly variable both from one patient to another and within a given patient [5]. The uncertainty surrounding the onset of an attack can cause great anxiety for patients given that the swelling-especially when affecting the airways-can be fatal. HAE may, therefore, have a substantial emotional impact on the patient as well as on his or her family. In a cross-sectional survey using the Hamilton Depression Inventory - Short Form questionnaire (HDI-SF), 42.5\% of HAE patients had scores indicative of depressive symptomatology [12]. Such findings suggest the importance of considering potential mental health impacts like stress, in addition to traditional treatment, in the clinical management of these patients in order to reduce the burden of HAE on daily life.

Some studies, including both interventional and case studies, have explored the health-related quality of life (HRQoL) impacts of HAE. Interventional studies have used general health status measures like the SF-36 and SF-12, and the Dermatology Life Quality Index (DLQI), which focuses on dermatological quality of life issues, and have found them to be associated with improvements in several quality of life areas, including both physical and psychological parameters [13-16]. However, authors noted limitations of the DLQI, as it was originally created for use in patients with chronic dermatological diseases with exacerbations such as psoriasis and refers to symptoms that may not be relevant for HAE. Also, it does not take acute attacks into consideration and therefore does not allow to measure patients' HRQoL both during an attack and in between attacks.

The SF-36 and SF-12 and general HRQoL measures are useful for making comparisons across disease areas, but they may fail to capture specific HRQoL manifestations of HAE. As Lumry and colleagues (2010) showed, HAE was associated with detriments in HRQoL across physical and mental health domains and in each subscale of both the SF-12 and HDI-SF [12]. However, without in-depth elaboration from patients, the interpretation of these impacts, particularly those that are primarily physical, is limited. Second, while depression was assessed by way of the HDI-SF, anxiety, arguably an important emotional marker for any chronic condition marked by sudden attacks, was not captured in this measure. Prior and colleagues are developing an international multi-language HAE-specific HRQoL measure for adults, the IHAE-QoL $[17,18]$. The pilot study has been completed in 12 countries (Argentina, Austria, Brazil, Canada, Denmark, France, Germany, Hungary, Israel, Poland, Romania, and Spain) and the psychometric study is being performed in order to validate this instrument ( $\mathrm{T}$ Caballero, personal communication). This diseasespecific questionnaire is expected to give more detailed and relevant data on HRQoL in HAE patients in the years ahead. However, this measure is, as of the publishing of the present article, still unavailable.

While there have been advances in our understanding of the burden of illness in HAE, significant gaps in our knowledge remain, particularly with regards to the humanistic and economic burden of the disease (Figure 2). There is a dearth of data on: the economic impact of HAE; comparisons of HAE treatment patterns, patient characteristics, and outcomes in different countries; the impact of HAE on adolescents; and qualitative research, including interviews and/or focus group studies with HAE patients. In addition, utility weights (preference values) have not been published for HAE. Such 


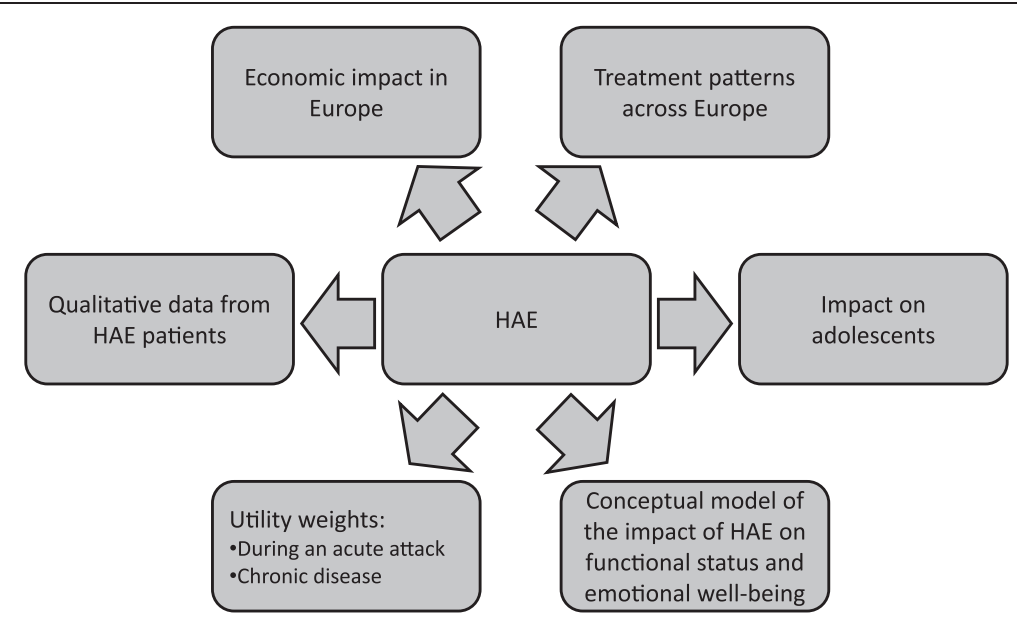

Figure 2 Gaps in the literature with regard to the humanistic and economic burden of HAE.

weights may be used to quality-adjust life expectancy for use in economic evaluations of medical interventions. Finally, no-one has yet developed a conceptual model visually depicting the relationships between HAE disease symptoms and more distal impacts, such as impact on career advancement and educational attainment.

There is also a critical need for better epidemiological data on HAE generally. The data from this study will help further inform such data. In addition, the findings likely can be compared with those from other studies, including HAE registries, such as the Sweha-Reg [19], the European Register of HAE [20], and observational studies such as the HAE nationwide survey conducted in Denmark [7].

Given the aforementioned gaps in our knowledge of HAE, the objective of the HAE Burden of Illness StudyEurope (HAE-BOIS-Europe) is to characterize the humanistic and economic burden of HAE from the patient perspective. This large-scale, scientifically robust, multicountry European study evaluates the real-world experience of HAE patients with respect to resource utilization and HRQoL burden of HAE in Germany, Denmark, and Spain. It collects qualitative data in addition to quantitative data to support a conceptual model of the patientperceived impacts of HAE on HRQoL, showing the quality of life and economic burden of HAE both in relation to acute attacks as well as the long-term experience of HAE. The present paper describes the development and plans for implementation of this multi-country European study, the initial findings of which will be publicly available in 2012.

\section{Methods}

The HAE-BOIS-Europe is a cross-sectional study, in which current and retrospective data are collected, conducted in Denmark, Germany and Spain, with participating patients being recruited from HAE centres of excellence, as well as HAE patient associations in each country. The two data collection components include a web- or paper-based questionnaire and one-on-one telephone interviews, designed to collect both quantitative and qualitative data from patients as illustrated in Figure 3. To be eligible for inclusion in the study, patients must have a diagnosis of HAE-I or HAE-II (with $\mathrm{C}-1$ inhibitor deficiency), be aged 12 years or older, have had at least one attack in the past six months, and demonstrate adequate fluency in the language in which they are taking the survey/interview. Patients with HAE-III or acquired angioedema are not eligible for inclusion into the study.

\section{Ethics review and patient confidentiality}

Prior to study recruitment, the protocol, including the questionnaire and interview guide, were translated into the native language of each target country and submitted to the ethics review board of each Centre as per the particular requirements of each Centre. The elements of country-specific regulations pertaining to consent procedures, disclosure of potential risks and benefits and subject confidentiality have been strictly observed. All study subjects are required to read and endorse a consent form (for participants aged 12-17, parents endorse the consent form and adolescents then endorse an assent form before data collection).

For the individual telephone interviews, the study coordinator screens patients, and those eligible and interested are scheduled for an anonymous telephone interview to be conducted by an interviewer trained in qualitative research by the research company Oxford Outcomes. All interviewers are fluent in the native language of the country in which the interview is taking place. 


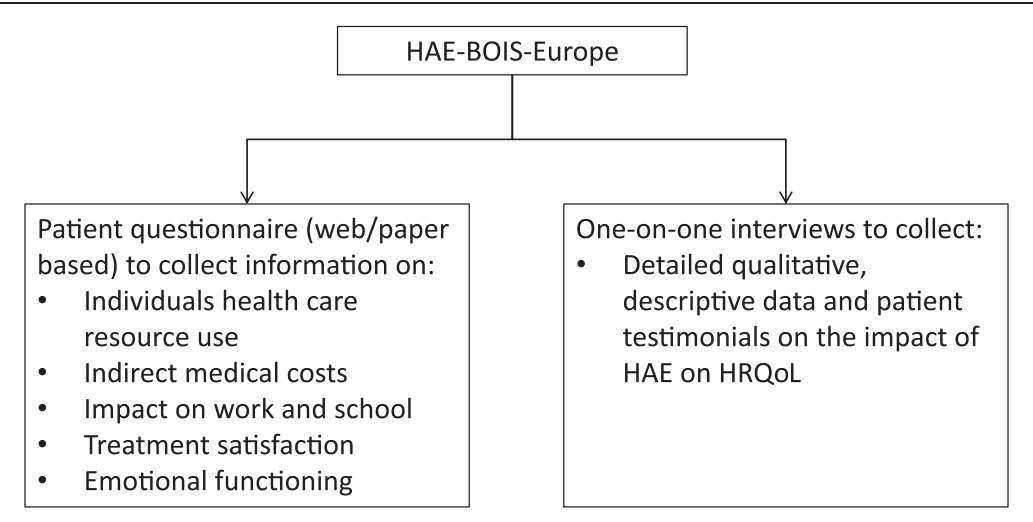

Figure 3 Study data collection components.

\section{Recruitment}

The principal investigators at the HAE Centres of Excellence in Frankfurt, Germany (Klinikum der Johann Wolfgang Goethe-Universität Frankfurt), Odense, Denmark (Odense Universitetshospital), and Madrid, Spain (Hospital Universitario La Paz) have contacted potentially eligible patients via mail, email or phone and/or advertised the study at the respective sites. In addition, the HAE patient associations in Denmark, Germany, and Spain have advertised the study on their website and/or have contacted members in their database. Contact has been made via phone, mail, or email with individuals who have noted that they would like to be contacted for HAE-related studies. The recruitment process has been designed to minimize selection bias. Specifically, in Denmark, almost all HAE patients have been invited; in Germany and Spain, all potentially eligible patients in the patient organization database, and a random sample of patients from the HAE Centers of Excellence, were invited.

Consistent with other burden of illness studies of rare conditions in Europe [21,22], the target sample size is 150. This sample size is sufficient to identify key impacts of HAE. The plan is to include equal numbers $(n=50)$ from each country, ensuring that each country-specific sample was generalizable through random sampling. For the telephone interviews, the target sample size is 30 patients with HAE (10 per country). Previous qualitative research has found that after twelve interviews, between 88 and $92 \%$ of themes can be identified [23].

The invitation letter includes a username and password used to access the survey; this allows individuals to return to the survey and complete it in multiple sittings. Patients who access the web link are screened online in the initial questions, and are led automatically to the consent forms and web survey. Patients without internet access call the study coordinator for a telephone screening; if the patient is eligible and interested, the study coordinator obtains the contact information to send the paper based consent form and survey. A summary of the study procedures is illustrated in Figure 4.

\section{Instruments}

The questionnaire is comprised of six sections intended to assess healthcare resource use and indirect costs. Examples of the data collected in each section are illustrated in Figure 5. The last section includes assessment of current anxiety and depression using the Hospital

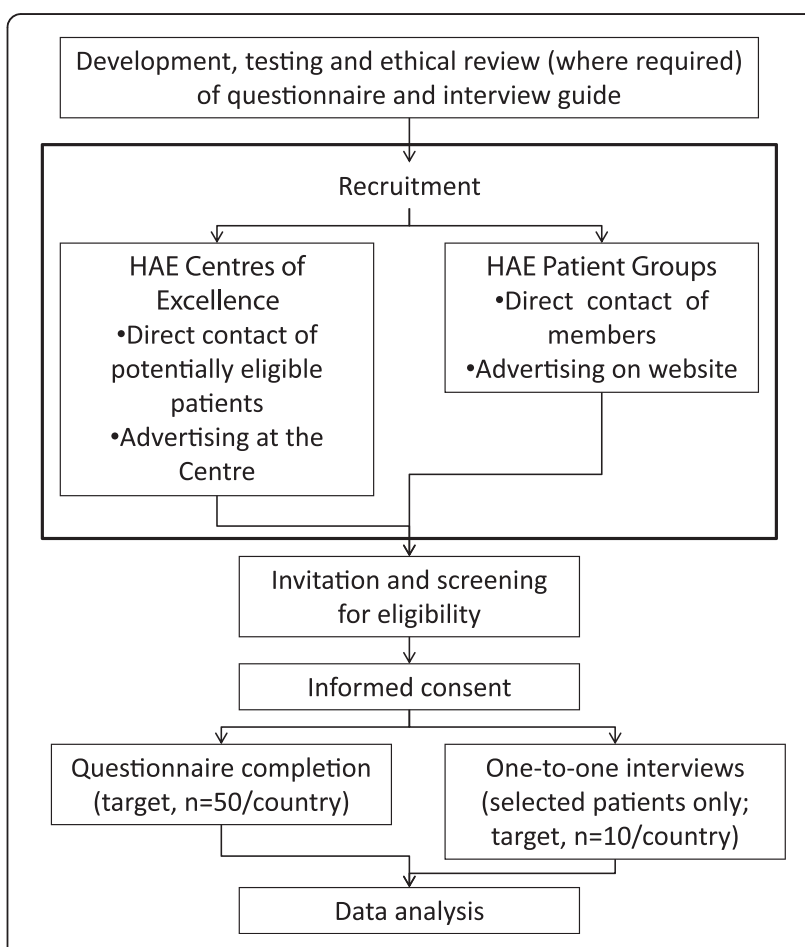

Figure 4 Summary of study procedures. 


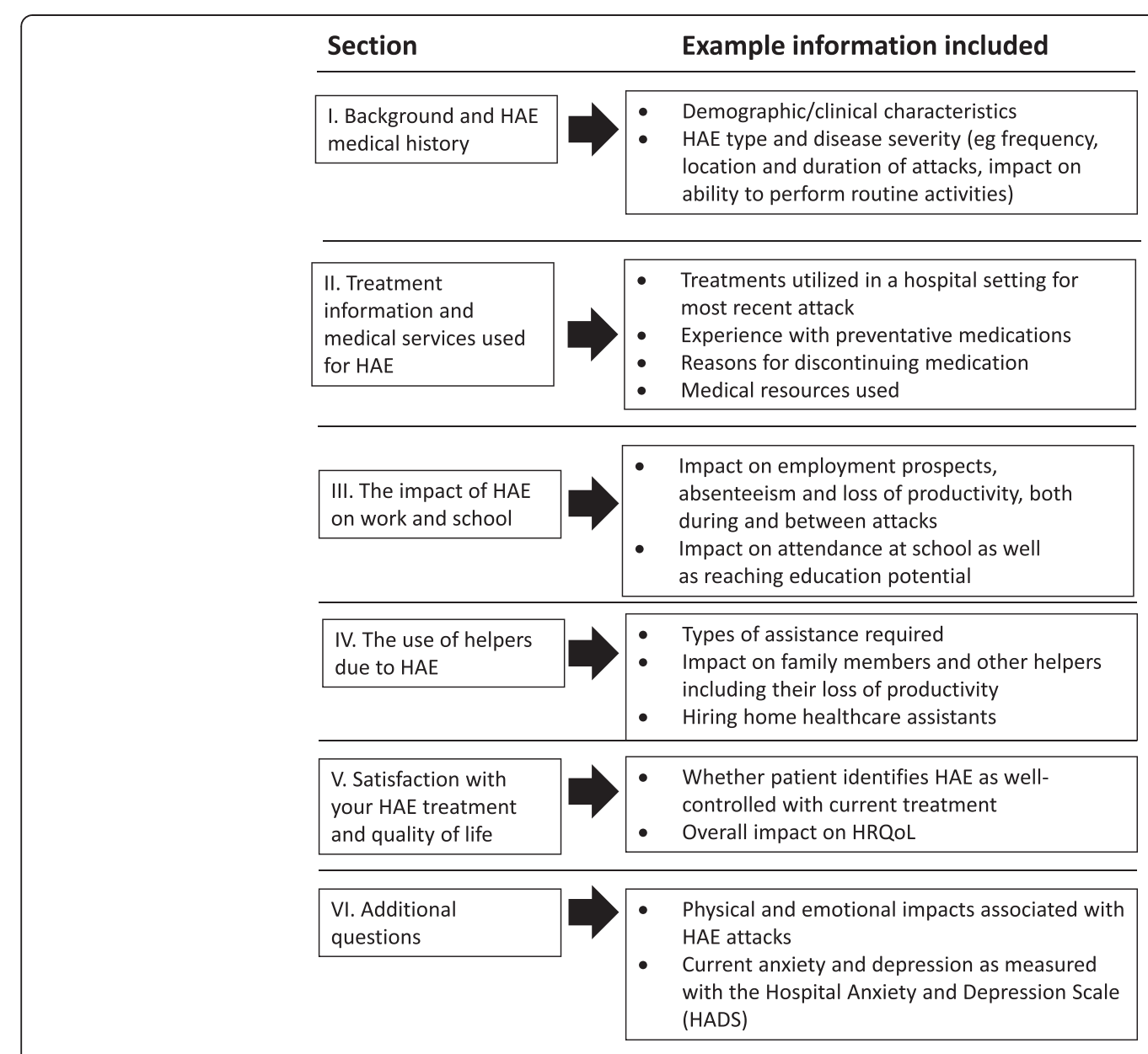

Figure 5 Overview of study questionnaire.

Anxiety and Depression Scale (HADS), a validated 14 item scale to assess anxiety and depression [24]. The HADS was developed specifically to identify the likelihood of 'caseness (or confirmed diagnostic condition)' with respect to anxiety disorders and depression among patients in non-psychiatric settings [24].

The one-on-one interviews are conducted using a semi-structured interview guide. The questions are largely open-ended, allowing the patient to discuss all the various ways that HAE impacts his/her life, such as what is it like to live with HAE, how HAE affects day-to-day activities, and impact of HAE on school and work advancement. Participants are also asked socio-demographic questions during the telephone interviews. Selected questions are the following:

- What is it like to live with HAE?

- Since being diagnosed with HAE, has your life changed? In what ways?

- What aspect of HAE is the most burdensome?

- When was your last HAE attack?
- Can you describe what this was like?

- Could you tell that you were about to have an attack?

- How much did your attack affect your activities? In what way?

- What does it feel like between attacks?

- How does having HAE affect your daily life?

- Does it affect your social life?

$\circ$ Does it affect your relationships?

- Does it affect your ability to work or attend school?

- Does this differ based on location of the attack?

- Are there any symptoms of HAE other than the attacks that impact your life in any way?

The surveys were pilot tested in Denmark, Spain, and Germany with nine participants who met the eligibility criteria and provided feedback on the survey. The pilot testers provided valuable feedback such as clarifying wording in certain questions, but no major changes to the surveys were required or proposed. In general, 
patients who took the pilot test found the survey understandable and highly relevant to their disease.

\section{Analysis}

Table 1 summarises the major anticipated analyses from HAE-BOIS-Europe. Descriptive analyses, including means, 95\% confidence intervals, and percentages, will be used to describe the medical resource utilization and work productivity variables in the survey. The Hospital Anxiety and Depression Scale (HADS) will be scored as recommended by the developer [24].

The analyses conducted in the HAE-BOIS-Europe study will yield such benefits as the potential to:

- Gain a comprehensive understanding of the humanistic and the direct and indirect resource impacts of HAE from the European patient perspective

- Provide feedback to patients and their families on the patient community experience with HAE

- Help advocate and raise awareness of HAE among policymakers and the global community

- Help raise awareness of the full impact of HAE among the clinical community and contribute to professional education on $\mathrm{HAE}$

This study also will provide an opportunity to explore different categorizations of HAE severity, for example, using attack frequency, duration of swelling, worst pain associated with attack, etc. and their associations with medical resource utilization and impact on ability to perform daily activities. Such analyses may help elucidate how well selected definitions of disease severity differentiate among functional and resource utilization impacts and may help inform clinical management decisions. Recent international consensus guidelines on HAE management, for example, do not provide detail on assessment of disease severity [10].

Table 1 Summary of the major anticipated analyses of data from HAE-BOIS-Europe

\begin{tabular}{|c|c|}
\hline Data source & Analyses \\
\hline \multirow[t]{3}{*}{ Survey data } & $\begin{array}{l}\text { Descriptive analyses, eg. Treatments used. Medical } \\
\text { resource utilization. Impact on work and school } \\
\text { productivity. Reliance on volunteer and paid helpers. } \\
\text { HADS scores and other HRQOL estimates }\end{array}$ \\
\hline & $\begin{array}{l}\text { Potential categorizations of HAE severity (frequency, } \\
\text { pain, duration, etc) }\end{array}$ \\
\hline & $\begin{array}{l}\text { Estimated health utility weights for: An acute HAE } \\
\text { attack - based on survey responses mapped to the } \\
\text { EQ-5D. Chronic disease - based on HADS scores } \\
\text { mapped to the EQ-5D }\end{array}$ \\
\hline Interviews & $\begin{array}{l}\text { Key concepts important to patients with HAE. } \\
\text { Providing context to survey-derived quantitative } \\
\text { findings. Providing input into the draft conceptual } \\
\text { model of HAE burden of illness }\end{array}$ \\
\hline
\end{tabular}

In addition, the study may provide data that can be used to estimate health utility (preference) weights for HAE. Health utilities are weights scaled from 0.0 (death) to 1.0 (full health). Such weights are used in cost-effectiveness evaluations to quality-adjust life expectancy, thereby producing quality-adjusted life years (QALYs) for medical interventions. Although the HAE-BOIS-Europe study does not directly collect utility data, we plan to estimate utilities for having an acute HAE attack as well as for chronic disease (in between attacks) using the survey data. Specifically, to estimate utilities for an acute attack, we plan to map response items from the burden of illness survey to corresponding items of the EQ-5D, a widely used utility questionnaire. These burden of illness items inquire about worst pain during the most recent attack, the duration that the attack prevented daily activities, the extent that the attack affected ability to perform regular activities, and anxiety about future attacks. We will map the responses to these items to the respective items within the EQ-5D and arrive at an estimated utility for an acute attack. The EQ-5D is a standardised instrument for use as a measure of health outcome that is applicable to a wide range of health conditions and is recommended by the UK's National Institute for Health and Clinical Excellence (NICE) [25]. A similar methodology will be used to estimate utilities for chronic HAE (in between attacks).

With respect to the one-on-one interviews, the interview scripts will be evaluated to identify key impacts of $\mathrm{HAE}$ and to provide context for enhancing interpretation of the survey findings. In qualitative research, there are no power calculations to determine sample size; rather, interviews should continue until saturation-that is, the point at which no new information is being obtained-is reached. In general, saturation is attained by the $10^{\text {th }}$ or $12^{\text {th }}$ interview. The findings will help substantiate and refine the conceptual model on the burden of illness of HAE.

\section{Draft conceptual model}

Conceptual models draw on a number of theories and concepts to help understand a particular problem in a specific population. Specifically, a conceptual model diagram shows relationships among a set of concepts such as disease symptoms, treatment, outcomes, and patient perceptions $[26,27]$. Conceptual models integrate biological and psychological aspects of health outcomes and can help to better understand the patient experience with a disease and specific areas that could benefit from treatment. Figure 6 shows a draft of such a conceptual model for HAE that illustrates both proximal as well as long-term impacts of HAE. This model was developed based on the initial review of the literature; it will be refined based on data from the current study. 


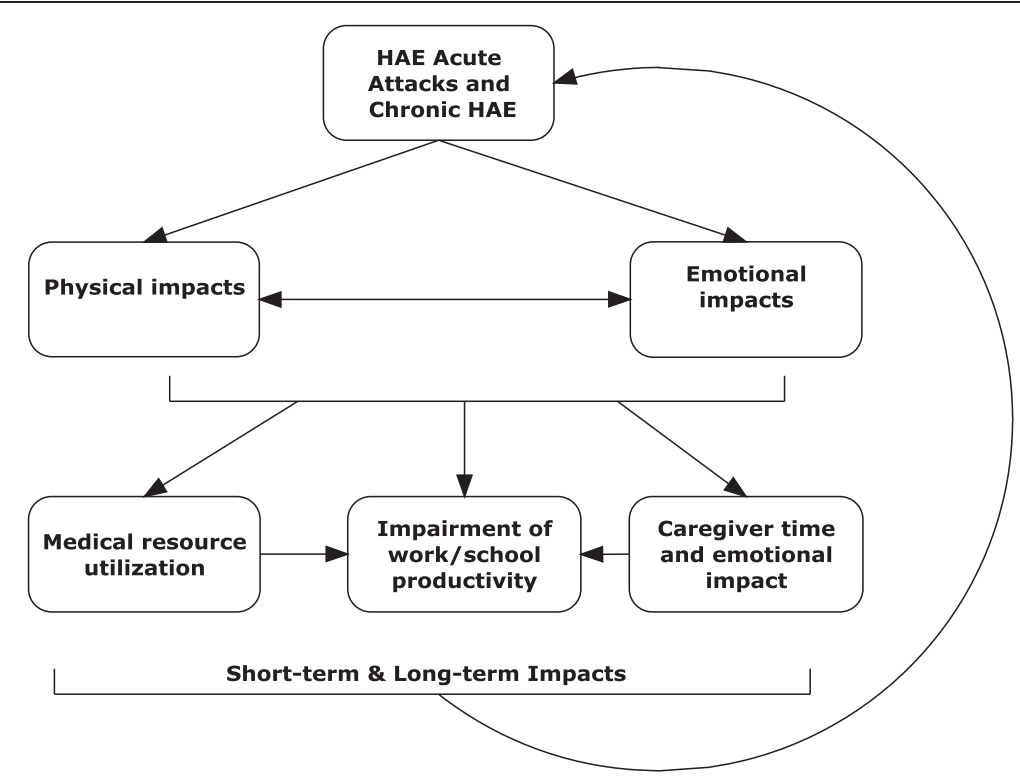

Figure 6 Humanistic and economic burden of HAE: draft conceptual model.

\section{Discussion and conclusion}

As with other rare conditions, knowledge of HAE can be limited even among medical professionals. There is therefore a need to collect and understand data describing the clinical, economic, and HRQoL impact of the disorder. While there has been a trend toward trying to better understand the burden of illness in HAE in recent years, a number of key gaps in the literature remain that have prevented a comprehensive understanding of the real-life experience of patients living with HAE and their families. A 2010 study by Wilson and colleagues [28] explored costs associated with HAE in the US and showed a considerable economic burden to patients, payers, and society at large. A study by Lumry et al. (2010) discussed humanistic impacts in the same sample but qualitative interviews with patients were not conducted [12]. Thus a study that includes both an economic evaluation and indepth qualitative research in Europe would be a useful addition to the literature.

Our study will build upon the US study [12,28], however, aspects of it will be more robust. For example, our study will: include adolescents; include patients recruited from patient organizations as well as medical centres; undergo ethics review at clinical sites to ensure data protection and sound methodology; include individual qualitative patient interviews; be conducted in parallel in three countries; and provide data on the humanistic burden in addition to the economic burden of illness. Further, it is hoped that the present study will provide a more comprehensive picture of the overall impact of HAE in that it will evaluate the impact both during acute HAE attacks and in-between attacks. The study will also allow the evaluation of any differences in outcomes for patients who report that their disease is well-controlled as opposed to those who consider their disease as poorly controlled. Ultimately, this study should help to better understand the impact of HAE from the patient perspective and may be very valuable in order to increase awareness of the impact of HAE on individuals and the respective health care systems in which HAE individuals are treated.

In conclusion, the HAE-BOIS Europe study is as the first study of its kind in Europe to obtain a comprehensive picture of HAE from the patient perspective. Its findings should help make HAE more visible in the European and global community, providing evidence forrational stakeholder discussion and informed interventions to help improve the lives of patients living with HAE.

\section{Competing interests}

This research was funded by ViroPharma SPRL.

Anette Bygum, MD has been involved in clinical research or educational events involving CSL Behring, Jerini/Shire, Sobi and ViroPharma.

Emel Aygören-Pürsün, MD has received sponsorship for educational purposes and has provided consultancy services or has participated in clinical trials sponsored by CSL-Behring, Jerini AG/Shire, Sobi and ViroPharma. Teresa Caballero, MD has received sponsorship for educational purposes, has been paid for providing consultancy services, or has taken part in clinical trials sponsored by Jerini AG/Shire, CSL-Behring, Pharming NV, and ViroPharma.

Kathleen Beusterien and Shadi Gholizadeh work for Oxford Outcomes Inc., an ICON Company, which consults for ViroPharma.

Patience Musingarimi receives consulting fees from ViroPharma. Suzanne Wait PhD receives consulting fees from ViroPharma. Henrik Boysen is the Executive Director of HAEi - International Patient Organization for C1 Inhibitor Deficiencies, which receives funding from most pharmaceutical companies, including ViroPharma, the sponsor of this study. 


\section{Authors' contributions}

All authors contributed to the study design. KB and SG drafted the manuscript, and all authors provided substantive input to the manuscript. All authors read and approved the final manuscript.

\section{Authors' information}

AB: Associate professor, HAE Centre Denmark, Department of Dermatology and Allergy Centre, Odense University Hospital, 5000 Odense C, Denmark EAP: Specialist for Internal Medicine and Haemostaseology, Department of Pediatrics, University Hospital Frankfurt, Germany; Member of the World Allergy Association (WAO) - HAE International Alliance Steering Committee TC: Allergy specialist; HAE expert; Consultant at Allergy Department from University Hospital La Paz, Madrid, Spain; Member of SEAIC, EAAACI, AAAAl; Coordinator of GEAB/SGAB (Spanish Group for the study of Angioedema induced by Bradykinin) within SEAIC (Spanish Society of Allergy and Clinical Immunology), researcher of the Biomedical Research Network on Rare Diseases U754 (CIBERER).

KB and SG: Consultants working at Oxford Outcomes, a subsidiary of ICON plc.

PM: Patience Musingarimi is a healthcare consultant currently working for ViroPharma.

SW: Suzanne Wait PhD is a health policy consultant and Director of SHW Health Ltd. She is also Senior Research Fellow at University College London. HB: Henrik Boysen is the Executive Director of HAEi - International Patient Organization for C1 Inhibitor Deficiencies and the President of the Danish HAE patient organization. He was diagnosed with HAE (type I) at the age of 17 years.

\section{Acknowledgements}

The authors acknowledge Andrea Cifelli, Louise Carrington, and Susan Laing at ApotheCom ScopeMedical for support with graphics creation for this manuscript. The authors also wish to acknowledge and thank the following organizations for their assistance with HAE patient recruitment for this study: Hudafdeling I og Allergicentret, Odense Universitetshospital, Denmark; Pädiatrische Onkologie, Hämatologie und Hämostaseologie, Klinikum der Johann Wolfgang Goethe-Universität Frankfurt, Germany; Servicio de Alergia, Hospital Universitario La Paz, Spain; HAEi - International Patient Organization for C1 Inhibitor Deficiencies; the Danish HAE Patient Association (patientforeningen HAE danmark); the German HAE Patient Association (HAE Vereinigung e.V.); and the Spanish Association for Hereditary Angioedema Due to $C 1$ Inhibitor Deficit (AEDAF).

\section{Author details}

${ }^{1}$ HAE Centre Denmark, Department of Dermatology and Allergy Centre, Odense University Hospital, 5000 Odense C, Denmark. ${ }^{2}$ Department of Pediatrics, Pediatric Hematology, Oncology, Hemostaseology and Cardiology, University Hospital, Johann Wolfgang Goethe University, Theodor-Stern-Kai 7, 60596 Frankfurt, Germany. ${ }^{3}$ Allergy Department, Hospital La Paz Health Research Center (IdiPaz), Biomedical Research Network on Rare Diseases U754 (CIBERER), University Hospital La Paz, Paseo de la Castellana 261, 28046 Madrid, Spain. ${ }^{4}$ Oxford Outcomes Inc, 7315 Wisconsin Ave. Ste 250W, Bethesda, MD 20814 USA. ${ }^{5}$ ViroPharma, Chatsworth House, 29 Broadway, Maidenhead, SL6 1LY UK. ${ }^{6}$ SHW Health Ltd, 40 Lena Gardens, London, W6 7PZ UK. ${ }^{7} \mathrm{HAEi}-$ International Patient Organization for C1 Inhibitor Deficiencies, Lindeparken 33, DK-6230 Roedekro, Denmark.

Received: 9 November 2011 Accepted: 15 April 2012 Published: 26 April 2012

\section{References}

1. Frank MM, Gelfand JA, Atkinson JP: Hereditary angioedema: The clinical syndrome and its management. Ann Intern Med 1976, 84:580-593.

2. Cicardi M, Bergamaschini L, Cugno M, Beretta A, Zingale LC, Colombo M, Agostoni A: Pathogenetic and clinical aspects of C1 inhibitor deficiency. Immunobiol 1998, 199:366-376.

3. Bork K, Ressel N: Sudden upper airway obstruction in patients with hereditary angioedema. Transfus Apher Sci 2003, 29:235-238.

4. Bork K, Meg G, Staubach P, Hardt J: Hereditary angioedema: New findings concerning symptoms, affected organs, and course. Am J Med 2006, 119:267-274.

5. Zuraw BL: Hereditary angioedema. N Engl J Med 2008, 359:1027-1036.
6. Nzeako UC, Frigas E, Tremaine WJ: Hereditary angioedema: A broad review for clinicians. Arch Intern Med 2001, 161:2417-2429.

7. Bygum A: Hereditary angio-oedema in Denmark: a nationwide survey. $\mathrm{Br}$ J Dermatol 2009, 161:1153-1158.

8. Agostoni A, Aygören-Pürsün E, Binkley KE, Blanch A, Bork K, Bouillet $L$, Bucher C, Castaldo AJ, Cicardi M, Davis AE, De Carolis C, Drouet C, Duponchel C, Farkas H, Fáy K, Fekete B, Fischer B, Fontana L, Füst G, Giacomelli R, Gröner A, Hack CE, Harmat G, Jakenfelds J, Juers M, Kalmár L, Kaposi PN, Karádi I, Kitzinger A, Kollár T, Kreuz W, Lakatos P, Longhurst HJ, Lopez-Trascasa M, Martinez-Saguer I, Monnier N, Nagy I, Németh E, Nielsen EW, Nuijens JH, O'grady C, Pappalardo E, Penna V, Perricone C, Perricone R, Rauch U, Roche O, Rusicke E, Späth PJ, Szendei G, Takács E, Tordai A, Truedsson L, Varga L, Visy B, Williams K, Zanichelli A, Zingale L: Hereditary and acquired angioedema: problems and progress: proceedings of the third C1 esterase inhibitor deficiency workshop and beyond. J Allergy Clin Immunol 2004, 114(3 Suppl):S51-S131

9. Roche O, Blanch A, Caballero T, Sastre N, Callejo D, López-Trascasa M: Hereditary angioedema due to $C 1$ inhibitor deficiency: patient registry and approach to the prevalence in Spain. Ann Allergy Asthma Immunol 2005, 94(4):498-503.

10. Bowen T, Cicardi M, Farkas H, Bork K, Longhurst HJ, Zuraw B, AygoerenPürsün E, Craig T, Binkley K, Hebert J, Ritchie B, Bouillet L, Betschel S, Cogar D, Dean J, Devaraj R, Hamed A, Kamra P, Keith PK, Lacuesta G, Leith E, Lyons H, Mace S, Mako B, Neurath D, Poon MC, Rivard GE, Schellenberg R, Rowan D, Rowe A, Stark D, Sur S, Tsai E, Warrington R, Waserman S, Ameratunga R, Bernstein J, Björkander J, Brosz K, Brosz J, Bygum A, Caballero T, Frank M, Füst G, Harmat G, Kanani A, Kreuz W, Levi M, Li H, Martinez-Saguer I, Moldovan D, Nagy I, Nielsen EW, Nordenfelt P, Rashef A, Rusicke E, SmithFoltz S, Späth P, Varga L, Xiang ZY: 2010 International consensus algorithm for the diagnosis, therapy and management of hereditary angioedema. Allergy Asthma Clin Immunol 2010, 6:24.

11. Gower RG, Busse PJ, Aygoren-Pursun E, Barakat A, Caballero T, Davis-Lorton M, Farkas H, Hurewitz D, Jacobs J, Johnston D, Lumry W, Maurer M: Hereditary angioedema caused by C1-esterase inhibitor deficiency: A literature-based analysis and clinical commentary on prophylaxis treatment strategies. WAO Journal 2011, 4:S9-S21.

12. Lumry WR, Castaldo AJ, Vernon MK, Blaustein MB, Wilson DA, Horn PT: The humanistic burden of hereditary angioedema: Impact on health-related quality of life, productivity, and depression. Allergy Asthma Proc 2010, 31 (5):407-414

13. Caballero T, Caminoa M, Prior N, Gomez-Traseira C, Perez E, Forjaz MJ: Health-related quality of life in adult patients with hereditary angioedema due to $\mathrm{C} 1$ inhibitor deficiency (HAE-C1-INH) as measured by SF-36v2: preliminary results of an international study. Allergy 2011, 66 (Suppl. 94):685. Abstr.

14. Bewtra A, Levy R, Wasserman $\mathrm{R}$, Jacobson $\mathrm{K}$, Craig T: Patients receiving ClINH treatment for hereditary angioedema report few health-related limitations on quality of life survey. Ann Allergy Asthma Immunol 2009, 103 (5 Suppl. 3):A115. Abstr.

15. Kreuz W, Martinez-Saguer I, Rusicke E, Aygören-Pürsün E, Klingebiel T: Impact of the Frankfurt HAE therapy protocol on Health-Related Quality of Life (HRQoL) in 50 patients with Hereditary Angioedema (HAE). J Allergy Clin Immunol 2009, 123:S116. Abstr.

16. Bygum A, Andersen KE, Mikkelsen CS: Self-administration of intravenous C1-inhibitor therapy for hereditary angioedema and associated quality of life benefits. Eur J Dermatol 2009, 19(2):147-151.

17. Prior N, Remor E, Gomez Traseira C, Pedrosa M, Lopez Serrano C, Caballero $\mathrm{T}$ : Development of a specific questionnaire for the assessment of healthrelated quality of life in adult patients with hereditary Angioedema due to $\mathrm{C} 1$ inhibitor deficiency (HAE) and cross-cultural validation proposal. $J$ Allergy Clin Immunol 2008, 121:S106. Abstr.

18. Prior N, Caballero T, Gomez-Traseira C, Pérez E, Caminoa M, Remor E, DVIHAE QoL Group: Development of an international specific questionnaire for the assessment of health-related quality of life in adult patients with hereditary angioedema due to $\mathrm{C} 1$ inhibitor deficiency (IHAE-QoL): pilot study preliminary results. Allergy 2011, 66(Suppl. 94):685. Abstr.

19. Mallbris L, Nordenfelt $P$, Björkander J, Lindfors A, Werner S, Wahlgren CF: The establishment and utility of Sweha-Reg: a Swedish population-based registry to understand hereditary angioedema. BMC Dermato/ 2007, 7:6.

20. Zingale LC, Bork K, Farkas H, Bygum A, Bouillet L, Caballero T, Longhurst H, Waage Nielsen E, Bilo B, Bucher C, Perricone R, Cicardi M: The European 
register of hereditary angioedema: experience and preliminary results. JACI 2007, 119(1):S276.

21. Weigl JA, Puppe W, Rockahr S, Schmitt HJ: Burden of disease in hospitalized RSV-positive children in Germany. Klin Padiatr 2002, 214 (6):334-342.

22. Tabolli S, Sampogna F, Di Petro C, Paradisi A, Uras C, Zotti P, Castiglia D, Zambruno G, Abeni D: Quality of life in patients with epidermylosis bullosa. Br J Dermatol 2009, 161(4):869-877. Epub 2009 May 11.

23. Guest $G$, Bunce A, Johnson L: How many interviews are enough? An experiment with data saturation and variability. Field Methods. 2006, 18 (1):59-82.

24. McDowell I: Measuring health: A guide to rating scales and questionnaires. Third edition. Oxford: Oxford University Press; 2006.

25. National Institute for Clinical Excellence: Guide to the Methods of Technology Appraisal (N0515). London: Briefing paper for methods review workshop on key issues in utility measurement; www.nice.org.uk/ TAMethodsReview 2004

26. Earp JA, Ennet ST: Conceptual models in health education research and practice. Health Ed Res 1991, 6:163-171.

27. Wilson I, Cleary P: Linking clinical variables with health-related quality of life A conceptual model of patient outcomes. J Am Med Assoc 1995, 273 (1):59-65.

28. Wilson DA, Bork K, Shea EP, Rentz AM, Blaustein MB, Pullman WE: Economic costs associated with acute attacks and long-term management of hereditary angioedema. Ann Allergy Asthma Immunol 2010, 104(4):314-320.

doi:10.1186/1471-5945-12-4

Cite this article as: Bygum et al:: The hereditary angioedema burden of illness study in Europe (HAE-BOIS-Europe): background and methodology. BMC Dermatology 2012 12:4.

\section{Submit your next manuscript to BioMed Central and take full advantage of:}

- Convenient online submission

- Thorough peer review

- No space constraints or color figure charges

- Immediate publication on acceptance

- Inclusion in PubMed, CAS, Scopus and Google Scholar

- Research which is freely available for redistribution 